\title{
Evaluation of Mother's Stress during Hospitalization Can Influence the Breastfeeding Rate. Experience in Intensive and Non Intensive Departments
}

\author{
S. Foligno ${ }^{1, *,+}$, A. Finocchi ${ }^{1}$, G. Brindisi ${ }^{2, *}$, A. Pace ${ }^{1}$, P. Amadio ${ }^{3}$, I. Dall'Oglio ${ }^{4}$, A. Portanova ${ }^{3}$, \\ P. Rossi ${ }^{1}$, A. Dotta ${ }^{3}$ and G. Salvatori ${ }^{3}$ \\ 1 Academic Pediatrics Department, Bambino Gesù Children's Hospital, Piazza di Sant'Onofrio, 4, \\ 00165 Rome, Italy; andrea.finocchi@uniroma2.it (A.F.); alessia.pace1992@gmail.com (A.P.); \\ paolo.rossi@opbg.net (P.R.) \\ 2 Pediatrics Department, Umberto I Hospital, Sapienza University, Viale Regina Elena 324, 00161 Rome, Italy \\ 3 Medical and Surgical Intensive Care Unit, Bambino Gesù Children's Hospital, Piazza di Sant'Onofrio, 4, \\ 00165 Rome, Italy; patrizia.amadio@opbg.net (P.A.); anna.portanova@opbg.net (A.P.); \\ andrea.dotta@opbg.net (A.D.); guglielmo.salvatori@opbg.net (G.S.) \\ 4 Professional Development, Continuing Education and Nursing Research Service, Bambino Gesù Children's \\ Hospital, Piazza di Sant'Onofrio, 4, 00165 Rome, Italy; immacolata.dalloglio@opbg.net \\ * Correspondence: silviafoligno@hotmail.com (S.F.); giulia.brindisi@gmail.com (G.B.); \\ Tel.: +39-329-2016608 (S.F.); +39-349-4566179 (G.B.) \\ + Current Address: Piazza di Sant'Onofrio, 4, 00165 Rome, Italy.
}

Received: 10 December 2019; Accepted: 23 January 2020; Published: 18 February 2020

\begin{abstract}
A mother's milk offers several benefits to infant's health, but, some factors may lead to a reduction in the duration of breastfeeding, such as maternal stress. The objective of our study is to determine if the rate of breastfeeding can be influenced by stress induced by infants' hospitalization. A preliminary observational non-randomized study was carried out in Bambino Gesù Children's Hospital between October 2016 and January 2017, in order to elucidate a possible relationship between breastfeeding and maternal stress, linked to hospitalization. We modeled the modified version of the PSS NICU (Parental Stressor Scale-neonatal intensive care unit) questionnaire, which investigated parental stress during hospitalization. This included 33 items with a score from 0 to 5. The overall score, high stress, was established at 85 points or higher. The principal statistically significant correlation was between 'high PSS score' and reduced breastfeeding during hospitalization ( $p$-value: 0.048 ; OR: 2.865, 95\%; CI: 1.008-8.146). This relation was not influenced by other descriptive characteristics of the mother. The PSS questionnaire can be an instrument to evaluate the influence of stress in breastfeeding and to monitor the rate and success of lactation. Our study highlights that the stress from hospitalization could influence the success of breastfeeding, mostly in intensive settings and during long hospitalizations.
\end{abstract}

Keywords: breastfeeding; stress; hospitalization

\section{Introduction}

The American Academy of Pediatrics recommends exclusive breastfeeding for about 6 months, with continuation for one year or longer as mutually desired by mother and infant [1]. A mother's milk offers several medical and neurodevelopmental benefits for health over short and long periods [2]. The protective effect is the result of the combination of duration and exclusivity of breastfeeding. Some factors may lead to a reduction of the duration of breastfeeding whether exclusive or partial, such as the advanced age of mothers, being nulliparous, the modality of delivery, low socioeconomic 
status (depending on settings), numbers of peers and parental relationship [3-5]. Breastfeeding can be influenced by chronic or acute stress, that could have an immediate or delayed effect [6]. Infant's hospitalization is a significant barrier against starting and continuing breastfeeding [7-9]. During this time, the mother may develop anxiety and fears that could influence the success of breastfeeding. Medical staff and nurses should not only focus on child care, but also support, promote and protect breastfeeding, to create a safe and comfortable environment $[7,10]$. In this perspective, breastfeeding and Kangaroo mother care (skin to skin contact) could help mothers to relax and subsequently, to take care of their own child [11]. This can be possible only by following a physiological breastfeeding process, which means stimulating suction practice, sustaining milk production, and therefore establishing a positive cycle [12]. Breastfeeding is an interactive process between mother and child and it is regulated by two main hormones: Prolactin (PRL) and oxytocin (OT), through an autocrine mechanism by the feedback inhibitor of lactation (FIL). Breastfeeding is a mechanism of demand and offer, where the suction activates a central reflex inducing PRL and OT production which allows milk ejection (ejection reflex). It is estimated that $85 \%$ of mothers breastfeed after birth, and over $97 \%$ continue with success when provided suitable support $[13,14]$. During infant's hospitalization, parental stress rises, especially in intensive care and in the neonatal intensive care unit (NICU) [15-17]. The objective of our study is to determine if the rate of breastfeeding can be influenced by maternal stress induced by the infant's hospitalization. The study was carried out in different departments to understand if the intensive setting is the main cause of mother's stress. Additionally, we studied how maternal stress was influenced by the level of information and education provided by medical and nursing staff during the hospitalization.

\section{Material and Methods}

\subsection{Study Design and Population}

This preliminary observational epidemiological non-randomized study was performed in the Bambino Gesù Children's Hospital, in order to elucidate a possible relationship between breastfeeding and maternal stress linked to hospitalization. To fully consider the potential stress factors associated with the hospital setting and environment, we provide an overview of how our medical departments and facilities are organized.

The Paediatric University Department of Bambino Gesù Children's Hospital occupies three different floors. On the ground floor, there is the semi-intensive area equipped with single rooms; the first floor is for the infectious and immunological departments, also equipped with single rooms for infectious disease isolation, and; the second floor is for the pediatric general wards, equipped with twin rooms. In general, the level of complexity and severity of the assistance required decreases from ground to second floor.

Considering the neonatal intensive unit, the intensive ward in Bambino Gesù Children's Hospital is not organized as a birth center; there is no rooming-in, so there are no single rooms for mother and child. This setting could contribute to raising parental stress.

The inclusion criteria selected for mothers of newborns or infants who were exclusive, complementary or predominantly breastfed, and admitted to Bambino Gesù Children's Hospital in the departments of neonatal intensive care and semi-intensive children care and pediatrics general ward, between October 2016 and January 2017. The exclusion criteria disqualified mothers who never experienced breastfeeding. Reviewing the existing literature, we studied different scales that evaluated the parental stress levels. On the basis of these scales, we modelled the modified version of the PSS NICU questionnaire (Parental Stressor Scale-neonatal intensive care unit) that investigated parental stress during hospitalization. This study was performed following good clinical practice (GCP), according to the Helsinki Declaration, and in line with the Ethics Committee of our Hospital. For this type of observational study, was sufficient the notification to the Ethics Committee of Bambino 
Gesù Children's Hospital. Thereafter, the study may start 60 days after notification using the silence / assent procedure.

Participants were asked to complete the questionnaire during hospitalization and within $72 \mathrm{~h}$ before discharge. These specific points in time were selected to record the quality of mother's stress during the period of hospitalization. To assess parental distress, the PSS NICU was developed from the Parental Stressor Scale: Pediatric ICU (PSS: PICU) by Carter (1985) [18] and Miles (1983) [19]. It was further refined by Miles et al. in 1993 [20], to measure the parental perception of stressors due to the physical, psychosocial and emotional environment of the neonatal intensive care unit. In the current study, a modified version of the PSS NICU [21] was presented in the original questionnaire [22], reformulating the English questions in a more straightforward Italian version, suitable to all educational levels. The validity and internal consistency of the scale has been confirmed in the USA [23] and the UK [22]. The questionnaire included 33 items, and was structured in three parts: Sights and sounds subscale; look and behavior subscale, and; communications with staff. A score from 0 to 5 was given to each item, referring to the stress perceived by the mother. The overall score which we decided to define as "high stress" was established at 85 points or higher, in order to create statistical correlations. The stress scale was interpreted by generating a summary of the score from each item. Those scores recorded as 0 were either "not applicable" or "not important" to the mother.

\subsection{Statistical Analysis}

For the statistical analysis, a software statistical package for social sciences was employed (SPSS Inc., Chicago, IL, USA). The baseline characteristics of patients were presented as percentages in the case of categorical variables, and as mean $\pm \mathrm{SD}$ of the average in the case of continuous variables. The categorical variables were compared by the Pearson $\chi 2$ test. As for non-categorical variables, the Student $t$-test was used. The statistically significant parent survey variables associated with each subscale score were then included in a stepwise multiple regression to predict each subscale score. Logistic regression was used to calculate odds ratios of parent survey variables and group attendance. Statistical significance was considered for $p$-values of equal to or less than 0.05 .

\section{Results}

From October 2016 to January 2017, the study enrolled 87 mothers of infants or newborns admitted to the Bambino Gesù Children's Hospital, who breastfed exclusively, complementarily or predominantly. While we offered the questionnaires to 100 mothers, only 87 mothers gave their consent to participate in the study. The general descriptive features of the mothers are reported in Tables 1 and 2, while the characteristics of children are reported in Table 3, and Figures 1 and 2.

Table 1. Descriptive characteristic of mothers.

\begin{tabular}{ccccc}
\hline & Min & Max & Median & DS \\
\hline Age & 20 & 44 & 33.24 & 5.025 \\
Number of Newborns & 1 & 9 & 1.77 & 1.053 \\
Number of Breastfed Newborns & 1 & 4 & 1.66 & 0.729 \\
Previous Pregnancy & 0 & 9 & 1.02 & 1.455 \\
\hline
\end{tabular}


Table 2. Descriptive characteristic of mothers.

\begin{tabular}{|c|c|}
\hline Nationality & \\
\hline Italian & $67(77 \%)$ \\
\hline Foreign & $20(23 \%)$ \\
\hline \multicolumn{2}{|l|}{ Education } \\
\hline Elementary school & $1(1.1 \%)$ \\
\hline Medium school & $46(52.9 \%)$ \\
\hline Degree & $40(46 \%)$ \\
\hline \multicolumn{2}{|l|}{ Occupation } \\
\hline Unemployed & $34(39.1 \%)$ \\
\hline Employed & $40(46 \%)$ \\
\hline Freelance & $5(5.7 \%)$ \\
\hline Laborer & $8(9.2 \%)$ \\
\hline \multicolumn{2}{|l|}{ Socio-Economic Status } \\
\hline Low & $9(10.3 \%)$ \\
\hline Medium & $71(81.6 \%)$ \\
\hline High & $7(8 \%)$ \\
\hline \multicolumn{2}{|l|}{ Relationship between Mother and Father } \\
\hline Split up & $30(34.5 \%)$ \\
\hline Married & $56(64.4 \%)$ \\
\hline Live together & $1(1.1 \%)$ \\
\hline \multicolumn{2}{|l|}{ Previous Pregnancy } \\
\hline Yes & $48(55.2 \%)$ \\
\hline No & $39(44.8 \%)$ \\
\hline \multicolumn{2}{|l|}{ Type of Birth } \\
\hline Natural & $44(50.6 \%)$ \\
\hline Caesarean section-Epidural & $38(43.7 \%)$ \\
\hline Caesarean section-General anesthesia & $5(5.7 \%)$ \\
\hline \multicolumn{2}{|l|}{ Smoke during pregnancy } \\
\hline Yes & $12(13.8 \%)$ \\
\hline No & $75(86.2 \%)$ \\
\hline \multicolumn{2}{|l|}{ Smoke during Hospitalization } \\
\hline Yes & $69(79.3 \%)$ \\
\hline No & $18(20.7 \%)$ \\
\hline
\end{tabular}

Table 3. Descriptive characteristic of children's population.

\begin{tabular}{ccccc}
\hline & Min & Max & Average & SD \\
\hline Gestational Age at Birth (g) & 23 & 39 & 31 & 11.31 \\
Weight of Birth(g) & 760 & 4100 & 2430 & 2361.74 \\
Weight at Admission(g) & 767 & 6000 & 3383.5 & 3700.3 \\
Weight at Discharge(g) & 2120 & 6540 & 4330 & 3125.42 \\
Hospitalization (days) & 7 & 40 & 23.5 & 23.33 \\
\hline
\end{tabular}




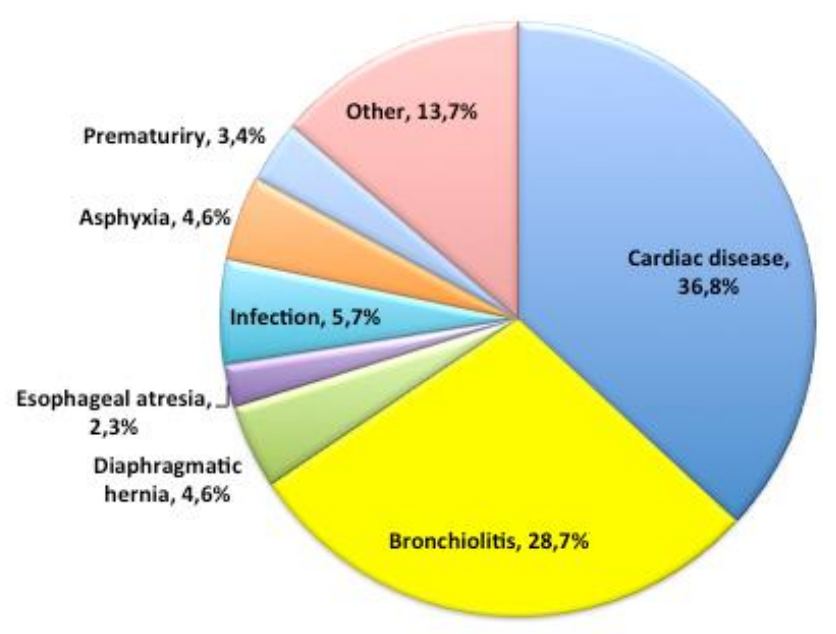

Figure 1. Percentage of diagnostic causes of admission of the general population.

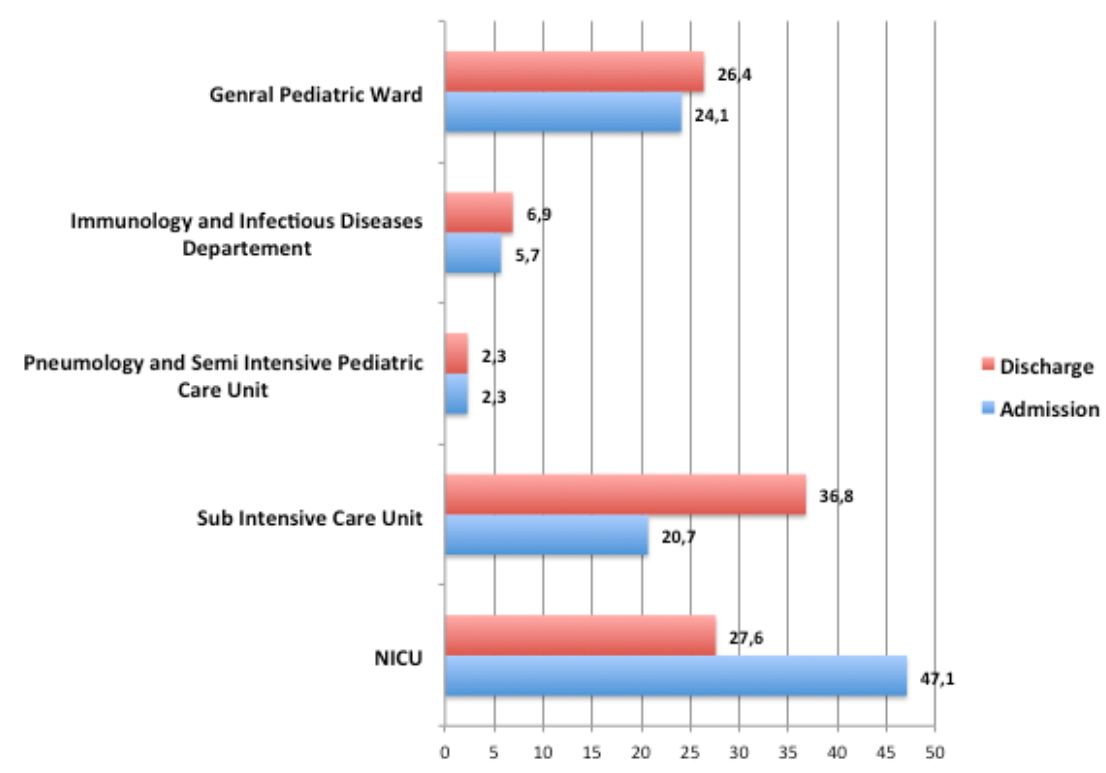

Figure 2. Percentage of population divided in the different departments.

The average age of mothers was 33.24 (20-44 years old) of which 45 (51.7\%) did not breastfeed exclusively, while 42 (48.3\%) breastfed exclusively. Moreover $48.3 \%$, approximately half of the total population, introduced infant formula during hospitalization.

Concerning the support, promotion and protection of breastfeeding, $24 \%$ of the total population did not receive any information or education about breastfeeding at all; 62 mothers (71.3\%) received limited information and education and nothing about benefits of breastfeeding; $82.2 \%$ of the total population reported an uncomfortable environment in the Hospital for practicing breastfeeding. Furthermore, $60.9 \%$ of mothers said that no help was given for issues linked to breastfeeding during hospitalization, and 52.9\% reported the sensation of reduction in milk production. This result was confirmed by objective data extracted from clinical medical reports, where $66.7 \%$ of the total population during hospitalization breastfed less than when the child was admitted.

Table 4, below, shows the results regarding the relationship between breastfeeding and stress as extracted from the modified PSS. 
Table 4. The table shows the maternal stress as measured by PSS $(n=87)$.

\begin{tabular}{|c|c|c|}
\hline Subscale and Components & Median & SD \\
\hline The presence of monitors and equipment & 2.20 & 1.421 \\
\hline The constant noise of equipment & 2.78 & 1.434 \\
\hline The sudden noise of monitor alarms & 3.32 & 1.521 \\
\hline The other sick babies in the room & 1.85 & 1.394 \\
\hline The large number of people working in the unit & 1.30 & 1.036 \\
\hline Having a ventilator breath for my baby & 2.33 & 1.853 \\
\hline Bruises and cuts on my baby & 1.87 & 2.067 \\
\hline Unusual color of my baby & 1.49 & 2.011 \\
\hline Unusual breathing of my baby & 2.30 & 2.075 \\
\hline Seeing my baby without breath & 2.01 & 2.127 \\
\hline The small size of my baby & 1.99 & 1.908 \\
\hline Tubes and equipment on or near my baby & 2.62 & 1.812 \\
\hline Seeing needles and tubes put in my baby & 2.07 & 2.128 \\
\hline When baby seemed to be in pain & 3.70 & 1.699 \\
\hline When baby looked sad & 3.67 & 1.420 \\
\hline The limp and weak appearance of my baby & 3.46 & 1.724 \\
\hline Being separated from my baby & 3.09 & 2.072 \\
\hline Not feeding my baby myself & 2.77 & 2.106 \\
\hline Not being able to care for my baby myself & 2.29 & 2.023 \\
\hline Not being able to hold my baby when I want & 2.59 & 2.165 \\
\hline Sometimes forgetting what my baby looks like & 0.86 & 1.571 \\
\hline Not being able to share my baby with other family members & 2.26 & 1.728 \\
\hline Feeling helpless and unable to protect my baby from pain and painful procedures & 3.37 & 1.818 \\
\hline Being afraid of touching or holding my baby & 1.91 & 1.762 \\
\hline Feeling staff are closer to my baby than I am & 1.68 & 1.762 \\
\hline Feeling not useful to help my baby & 2.82 & 1.775 \\
\hline Feeling staff do not explain in a clear way & 2.09 & 1.783 \\
\hline Feeling staff explain a different clinical situation to reality & 2.13 & 1.605 \\
\hline Having relation with a several different professional figures (nurse, doctors, interns) & 1.90 & 1.414 \\
\hline Feeling staff does not give information about the clinical status of my baby & 2.78 & 2.088 \\
\hline Feeling staff do not know the real needs of my baby & 2.52 & 1.934 \\
\hline Feeling sad about leaving my baby alone & 2.69 & 1.937 \\
\hline Feeling sad because my baby is in hospital & 4.69 & 0.556 \\
\hline
\end{tabular}

The score "high PSS" is correlated to the reduction of breastfeeding during hospitalization. Through a single linear regression, a significant relation between the two variables above was found ( $p$-value: 0.048; OR: 2.865, 95\%; CI: 1.008-8.146). Applying a multiple linear regression, this correlation was not influenced by subjective variables (mother's age, nationality, profession, education, socio-economic status, relationship, previous pregnancy, previous breastfed newborns) with a significant correlation ( $p$-value: 0.002 ; OR: $0.207,95 \%$; CI: $0.53-0.8$ ). So the variable itself (less breastfed during hospitalization) was related with "high stress score". This relation was not influenced by information given to the mothers during hospitalization ( $p$-value: 0.025 ; OR: $3.695 \%$; CI: $1.74-11.4$ ). No correlation was found between "moderate or high stress" and "sensation of milk reduction". The intensive setting (semi and intensive neonatal unit) presented a higher number of stressed mothers than other departments. Overall, applying a single linear regression between "high PSS scores" and departments, a strong correlation with the admission to NICU was noted ( $p$-value: 0.003; OR: 0.225, 95\%; CI: 0.083-0.609). Finally it was detected a significant relation between the duration of hospitalization (above of 20 days) and "high PSS score" (p-value: 0.028; OR: 3.54, 95\%; CI: 1.148-10.955). To check the influence of each part of PSS on breastfeeding rates, was conducted a linear regression between each part of the PSS and "less breastfed". The third part of PSS questionnaire had a significant correlation with "less breastfed" ( $p$-value: 0.039 ; OR: $1.042,95 \%$; CI: 1.0-1.08). This part of PSS questionnaire referred to parental role. 


\section{Discussion}

Stress is the organism's total response to environmental demands or pressures. There are different types of stress, negative and positive. The first one occurs when stressful stimuli lead to a progressive strain, until a break of psychological and physical barriers, while positive stress or eustress is a complex of stimuli that trains the ability to adapt [24]. Eustress represents a type of energy utilized to reach a goal and so this stress helps to make personal improvement. One of the best examples of adaptation to stress is breastfeeding. Indeed, oxytocin contributes to mother's relaxation and promotes a sense of childcare, while skin-to-skin contact facilitates PRL release $[25,26]$. Beta-endorphins are hormones of pleasure reward, and childcare contributes to an increase in their levels. This also could represent a central motivation of pleasure [27]. Moreover, beta-endorphins are released from human milk and swallowed by the child, representing a stimulus of reward for the child [27]. Stress caused by an irrational fear of insufficient breastfeeding can lead to depressive disorder [28], which is one of the most common causes for not starting or continuing with breastfeeding exclusively $[29,30]$. The mother's milk becomes more important in the case of a newborn, in particular those who are admitted to the hospital, especially to intensive care unit. In fact, it reduces the risk of infectious and intestinal diseases and helps to fortify the immunological system of these weak patients. Moreover, it creates a unique relationship, favored by skin-to-skin contact. Only one study in the literature has showed social barriers as a stress factor capable to reduce the commencement of breastfeeding [31]. No study has demonstrated the influence of maternal stress on lactation, caused by hospitalization. In contrast to other studies, in our report, breastfeeding was not influenced by mother's age, smoking habit or previous pregnancy. Degree of education and profession were not linked to maternal stress, which is different to the data showed in the literature [32]. As highlighted by Holmes et al. (2013) [33], the importance of education and information about breastfeeding both before and during pregnancy is critical. In our study, 62 mothers (71.3\% of total) reported that no information or education on the benefits of breastfeeding was provided to them. Nevertheless, no significant correlation was found between lack of information and "high PSS score". Therefore, it is critical that an effective communication with mothers is conducted [34]. In our study, $60.9 \%$ of the mothers had no help to solve and cope with problems related to breastfeeding. During hospitalization, a number of studies highlighted that parental stress rises, particularly in intensive care setting. Several studies validated and reported the utilization of PSS, adapted to different settings, namely, general pediatric unit (GPU), pediatric intensive care (PIC) and neonatal intensive care unit (NICU) $[15,17,20]$. Our goal was also to analyze the influence of different settings on mother's stress levels. In the study conducted by Turner et al. (2015) in a NICU, the results showed that mothers were stressed in all fields on the parental stress scale (sight and sound, baby behavior and relation and role of parent) [35]. Similar to Turner's analysis, we found a relation between "high PSS score" and the intensive care setting. From our study, we reported that the "high PSS score" of the third part of the PSS questionnaire indicated a strong relation to a reduction in breastfeeding. Additionally, it was reported in another study that a "high PSS score" in cases of long hospitalization (more than 20 days) indicated increased stress that was linked to seven days or more of hospitalization [32]. The principal statistically significant correlation was between "high PSS score" and reduced breastfeeding during hospitalization ( $p$-value: 0.048; OR: 2.865, 95\%; CI: 1.008-8.146). This relation was not influenced by other descriptive characteristics of the mother. There are some limitations to this study, including that the population was not uniform (different age and basal characteristics). Nevertheless, this population still provides valuable information about the environment and the different settings. Another limitation is the language barrier, where some units of the population did not have full comprehension of the Italian language. It is important to state that this was a preliminary pilot study and additional follow-up studies may be necessary.

\section{Conclusions}

The data from our study show that in a specialized pediatric hospital, the level of information and education regarding the benefits of breastfeeding was insufficient. Furthermore, there was a lack of 
necessary support to overcome the difficulties associated with hospitalization, which was correlated to a reduction in breastfeeding. Improvements are needed to assure an increase in the percentage of breastfeeding mothers during hospitalization. It is an aim and priority of WHO/UNICEF (World health organization/ United Nations Children's Fund) initiatives to promote the frequent training and distribution of information on protection, promotion and support of breastfeeding to mothers. In this scenario of hospitalization, the implementation of a shared protocol between nurse and pediatrician to protect breastfeeding is fundamental. A dedicated staff and a comfortable environment should be the standard of care for all mothers. As for our findings regarding the third part of the PSS questionnaire, it seems important to place the maternal role at the center of care during hospitalization. Our study highlights that the stress from hospitalization could influence the success of breastfeeding. This is particularly true in intensive care settings, and during long hospitalizations. Breastfeeding creates a unique relationship between mother and child, thus reducing the negative effects linked to hospital stress. Finally, this study showed that the PSS questionnaire can be an instrument to evaluate the influence of stress in breastfeeding and may be used to monitor the rate and success of lactation in intensive care settings.

Author Contributions: Conceptualization, S.F., G.B., G.S.; methodology, S.F. and A.P. (Alessia Pace); formal analysis, S.F. and A.P. (Alessia Pace); investigation, A.P. (Alessia Pace), P.A., I.D., A.P. (Anna Portanova); writing-original draft preparation, S.F., G.B., G.S.; writing—-review and editing, S.F., G.B., G.S.; supervision, G.S., A.F., P.R., A.D. All authors have read and agreed to the published version of the manuscript.

Funding: This research received no external funding.

Conflicts of Interest: The authors declare no conflict of interest.

\section{References}

1. Baby-Friendly Hospital Initiative: Revised, Updated and Expanded for Integrated Care; WHO Guidelines Approved by the Guidelines Review Committee; World Health Organization: Geneva, Switzerland, 2009.

2. Section on B. Breastfeeding and the use of human milk. Pediatrics 2012, 129, e827-e841. [CrossRef]

3. Committee Opinion No. 570: Breastfeeding in underserved women: Increasing initiation and continuation of breastfeeding. Obstet. Gynecol. 2013, 122 Pt 1, 423-428.

4. Unmarried_Women.pdf CTDBBtUWIoCaYAawcowcuBt. Available online: https://www.childtrends.org/wpcontent/uploads/2015/03/75_Births_to_Unmarried_Women.pdf (accessed on 3 December 2015).

5. Kenny, L.C.; Lavender, T.; McNamee, R.; O'Neill, S.M.; Mills, T.; Khashan, A.S. Advanced maternal age and adverse pregnancy outcome: Evidence from a large contemporary cohort. PLoS ONE 2013, 8, e56583. [CrossRef] [PubMed]

6. Lau, C. Effects of stress on lactation. Pediatr. Clin. N. Am. 2001, 48, 221-234. [CrossRef]

7. Salvatori, G.; Foligno, S.; Occasi, F.; Pannone, V.; Valentini, G.B.; Dall'Oglio, I.; Bagolan, P.; Dotta, A. Human milk and breastfeeding in surgical infants. Breastfeed. Med. Off. J. Acad. Breastfeed. Med. 2014, 9, 491-493. [CrossRef] [PubMed]

8. Khasawneh, W.; Khasawneh, A.A. Predictors and barriers to breastfeeding in north of Jordan: Could we do better? Int. Breastfeed. J. 2017, 12, 49. [CrossRef] [PubMed]

9. Mattsson, E.; Funkquist, E.L.; Wickstrom, M.; Nyqvist, K.H.; Volgsten, H. Healthy late preterm infants and supplementary artificial milk feeds: Effects on breast feeding and associated clinical parameters. Midwifery 2015, 31, 426-431. [CrossRef]

10. Alakaam, A.; Lemacks, J.; Yadrick, K.; Connell, C.; Choi, H.W.; Newman, R.G. Breastfeeding Practices and Barriers to Implementing the Ten Steps to Successful Breastfeeding in Mississippi Hospitals. J. Hum. Lact. 2018, 34, 322-330. [CrossRef] 
11. Bystrova, K.; Widström, A.M.; Matthiesen, A.S.; Ransjö-Arvidson, A.B.; Welles-Nyström, B.; Wassberg, C.; Vorontsov, I.; Uvnäs-Moberg, K. Skin-to-skin contact may reduce negative consequences of "the stress of being born": A study on temperature in newborn infants, subjected to different ward routines in St. Petersburg. Acta Paediatr. 2003, 92, 320-326. [CrossRef]

12. Zanardo, S.; Nicolussi, F.; Favaro, D.; Faggian, M.; Plebani, F.; Marzari, F.; Freato, V. Effect of postpartum anxiety on the colostral milk beta-endorphin concentrations of breastfeeding mothers. J. Obstet. Gynaecol. J. Inst. Obstet. Gynaecol. 2001, 21, 130-134. [CrossRef]

13. Giovannini, M.; Banderali, G.; Radaelli, G.; Carmine, V.; Riva, E.; Agostoni, C. Monitoring breastfeeding rates in Italy: National surveys 1995 and 1999. Acta Paediatr. 2003, 92, 357-363. [CrossRef] [PubMed]

14. Dall'Oglio, I.; Salvatori, G.; Stendardi, M.C.; Bonci, E.; D'Agostino, G. Breastfeeding in neonatal intensive care: Description of a change. Assist. Inferm. Ric. Air 2004, 23, 221-227. [PubMed]

15. Agazio, J.B.; Buckley, K.M. Revision of a Parental Stress Scale for use on a pediatric general care unit. Pediatr. Nurs. 2012, 38, 82-87. [PubMed]

16. Miles, M.S.; Brunssen, S.H. Psychometric properties of the parental stressor scale: Infant hospitalization. Adv. Neonatal Care Off. J. Natl. Assoc. Neonatal Nurses 2003, 3, 189-196. [CrossRef]

17. Samra, H.A.; Dutcher, J.; McGrath, J.M.; Foster, M.; Klein, L.; Djira, G.; Hansen, J.; Wallenburg, D.; Dowling, D. Effect of Skin-to-Skin Holding on Stress in Mothers of Late-Preterm Infants: A Randomized Controlled Trial. Adv. Neonatal Care Off. J. Natl. Assoc. Neonatal Nurses 2015, 15, 354-364. [CrossRef]

18. Carter, M.C.; Miles, M.S.; Buford, T.H.; Hassanein, R.S. Parental environmental stress in pediatric intensive care units. Dimens. Crit. Care Nurs. Dccn 1985, 4, 180-188. [CrossRef]

19. Miles, M.S.; Carter, M.C. Sources of parental stress in pediatric intensive care units. Child. Health Care J. Assoc. Care Child. Health 1983, 11, 65-69. [CrossRef]

20. Miles, M.S.; Funk, S.G.; Carlson, J. Parental Stressor Scale: Neonatal intensive care unit. Nurs. Res. 1993, 42, 148-152. [CrossRef]

21. Miles, M.S. Parental Stress Scale: Neonatal Intensive Care Unit 2002. Available online: https://doi.org/10. 1080/02646830601117258 (accessed on 17 February 2020).

22. Reid, T.; Bramwell, R. Using the Parental Stressor Scale: NICU with a British sample of mothers of moderate risk preterm infants. J. Reprod. Infant. Psychol. 2003, 21, 279-291. [CrossRef]

23. Miles, M.S.; Carlson, J.; Brunssen, S. The nurse parent support tool. J. Pediatr. Nurs. 1999, 14, 44-50. [CrossRef]

24. Milsum, J.H. A model of the eustress system for health/illness. Behav. Sci. 1985, 30, 179-186. [CrossRef] [PubMed]

25. Dimitraki, M.; Tsikouras, P.; Manav, B.; Gioka, T.; Koutlaki, N.; Zervoudis, S.; Galazios, G. Evaluation of the effect of natural and emotional stress of labor on lactation and breast-feeding. Arch. Gynecol. Obstet. 2016, 293, 317-328. [CrossRef] [PubMed]

26. Buckley, S.J. Executive Summary of Hormonal Physiology of Childbearing: Evidence and Implications for Women, Babies, and Maternity Care. J. Perinat. Educ. 2015, 24, 145-153. [CrossRef] [PubMed]

27. Zanardo, V.; Nicolussi, S.; Carlo, G.; Marzari, F.; Faggian, D.; Favaro, F.; Plebani, M. Beta endorphin concentrations in human milk. J. Pediatr. Gastroenterol. Nutr. 2001, 33, 160-164. [CrossRef] [PubMed]

28. Yang, L.; Zhao, Y.; Wang, Y.; Liu, L.; Zhang, X.; Li, B.; Cui, R. The Effects of Psychological Stress on Depression. Curr. Neuropharmacol. 2015, 13, 494-504. [CrossRef]

29. Taj, R.; Sikander, K.S. Effects of maternal depression on breast-feeding. JPMA J. Pak. Med. Assoc. 2003, 53, 8-11.

30. Pippins, J.R.; Brawarsky, P.; Jackson, R.A.; Fuentes-Afflick, E.; Haas, J.S. Association of breastfeeding with maternal depressive symptoms. J. Women's Health 2006, 15, 754-762. [CrossRef]

31. Insaf, T.Z.; Fortner, R.T.; Pekow, P.; Dole, N.; Markenson, G.; Chasan-Taber, L. Prenatal stress, anxiety, and depressive symptoms as predictors of intention to breastfeed among Hispanic women. J. Women's Health 2011, 20, 1183-1192. [CrossRef]

32. Chourasia, N.; Surianarayanan, P.; Adhisivam, B.; Vishnu Bhat, B. NICU admissions and maternal stress levels. Indian J. Pediatr. 2013, 80, 380-384. [CrossRef]

33. Holmes, A.V. Establishing successful breastfeeding in the newborn period. Pediatr. Clin. N. Am. 2013, 60, 147-168. [CrossRef] 
34. Brett, J.; Staniszewska, S.; Newburn, M.; Jones, N.; Taylor, L. A systematic mapping review of effective interventions for communicating with, supporting and providing information to parents of preterm infants. BMJ Open 2011, 1, e000023. [CrossRef] [PubMed]

35. Turner, M.; Chur-Hansen, A.; Winefield, H.; Stanners, M. The assessment of parental stress and support in the neonatal intensive care unit using the Parent Stress Scale-Neonatal Intensive Care Unit. Women Birth 2015, 28, 252-258. [CrossRef] [PubMed]

(C) 2020 by the authors. Licensee MDPI, Basel, Switzerland. This article is an open access article distributed under the terms and conditions of the Creative Commons Attribution (CC BY) license (http://creativecommons.org/licenses/by/4.0/). 